\section{Transfemoral TAVI and aortic calcification: the destructive impact of endogenous calcium}

Transfemoral transcatheter aortic valve implantation (TAVI) procedure was performed in an elderly patient with degenerative aortic stenosis using a $23 \mathrm{~mm}$-Edwards-Sapien XT bioprosthesis (Edwards Lifesciences, Irvine, California, USA). In addition to degenerative aortic stenosis, the patient also had severe calcification in the descending aorta. After positioning the $16 \mathrm{~F}$-e-sheath through the right femoral artery, the bioprosthesis was advanced with a retroflex catheter to the ascending aorta in the usual fashion. Just before crossing the aortic valve, a deformation of the cobalt-chromium stent with an outward bending of two struts was observed, which had been caused by resistance of
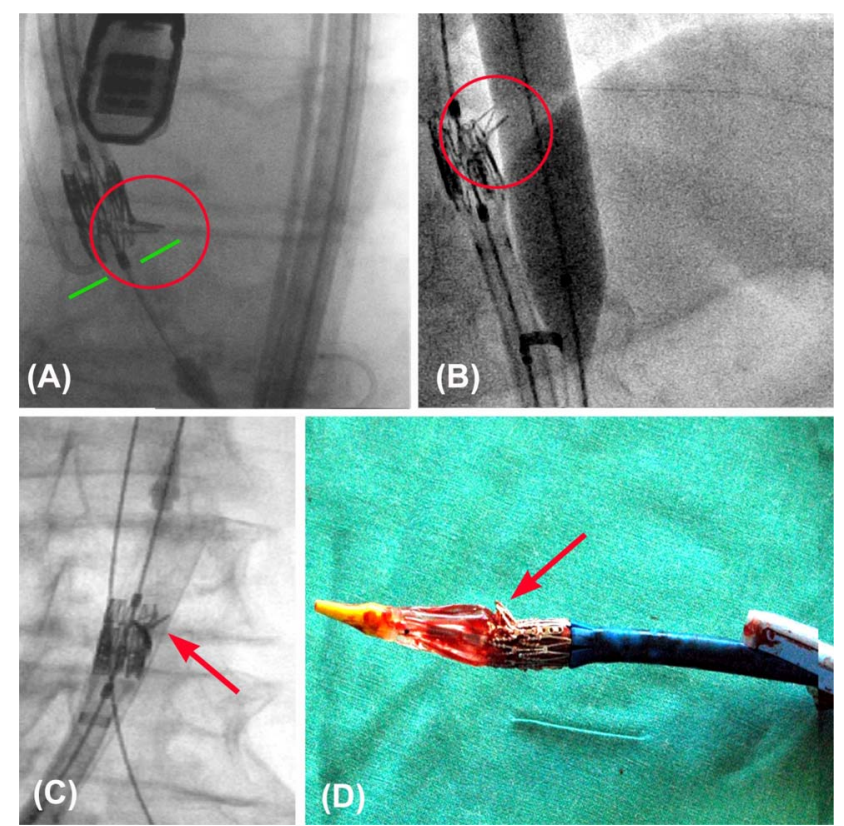

Figure 1 A deformation of the cobalt-chromium stent with an outward bending of two stent struts is caused by resistance of endogenous calcium in the descending aorta during advancement of the transcatheter aortic valve implantation device (A and D).

A 'reshaping' manoeuvre by balloon inflation alongside the device fails due to repetitive balloon rupture (B). The device is therefore retracted into the collapsed e-sheath after dilatation of the e-sheath (C). endogenous calcium plaques in the descending aorta during catheter introduction (figure $1 \mathrm{~A}$ and $\mathrm{D}$ ). The device was therefore retracted into the descending aorta and a 'reshaping' manoeuvre was attempted by balloon inflation alongside the valve (figure 1B). This, however, failed due to repetitive balloon rupture. To retract the device into the collapsed e-sheath, a 0.035 -inch straight guidewire was forcefully advanced into the sheath alongside the retroflex catheter resulting in the dilatation of the sheath (figure 1C). This eventually facilitated the stepwise retraction of the deformed valve into the sheath. Catheter and sheath were then removed and the TAVI procedure was successfully performed with a new device.

This case demonstrates that in patients with extensive calcification of the aorta, particular care should be taken during transfemoral catheter introduction. Although we believe that the presence of extensive endogenous calcium itself does not generally object to transfemoral access, transapical valve implantation might be an alternative in patients with bulky aortic calcification.

\section{Alexander Lauten, Hans R Figulla, Markus Ferrari}

Department of Cardiology, Angiology, Pneumology and Intensive Care Medicine, University Heart Center Jena, Jena, Germany

Correspondence to Dr Alexander Lauten, Department of Cardiology, Angiology, Pneumology and Intensive Care Medicine, University Heart Center Jena, Erlanger Allee 101, Jena 07747, Germany; alexander.lauten@med.uni-jena.de

Contributors AL wrote the manuscript and contributed to patient treatment. HRF and MF revised the manuscript and contributed to patient treatment.

Competing interests None.

Provenance and peer review Not commissioned; internally peer reviewed.

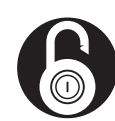

\section{OPEN ACCESS}



Open Access This is an Open Access article distributed in accordance with the Creative Commons Attribution Non Commercial (CC BY-NC 3.0) license, which permits others to distribute, remix, adapt, build upon this work non-commercially, and license their derivative works on different terms, provided the original work is properly cited and the use is non-commercial. See: http://creativecommons.org/licenses/by-nc/3.0/

To cite Lauten A, Figulla HR, Ferrari M. Heart 2013;99:971.

Received 9 December 2012

Revised 29 December 2012

Accepted 26 January 2013

Published Online First 8 March 2013

Heart 2013;99:971. doi:10.1136/heartjnl-2012-303482 